\title{
An operational perspective of mine backfill
}

\author{
ML Bloss BHP Billiton, Australia
}

\section{$1 \quad$ Introduction}

Backfilling of voids created by mining is a fundamental component of most underground stoping operations. Without backfill, these operations would be less safe, less productive and shorter in life. Backfilling does not come free of cost and risk, however, and it is this balance of influences on the mining operation that makes successful backfilling such a technical and operational challenge.

This paper aims to gather and discuss a wide range of key operational issues, challenges and opportunities associated with mine backfilling. It is not intended to be a scientific paper worthy of peer review (although it does refer to technical issues where they are relevant to operational practices), merely a collection of thoughts based on the author's personal experience over 24 years of research, technical, planning, operational and project roles associated with underground operations that use mine backfill. These operations have utilised both uncemented and cemented varieties (where applicable) of hydraulic and paste fills, aggregate and rockfills, and combinations of these fill types, in cut-and-fill, benching and open stoping operations. To obtain appropriate technical information, the author suggests referring to the many excellent papers published over the years, particularly those in the previous ten international mine backfill symposia.

The discussion is divided into topics that cover key operational aspects of mine backfill, namely: systems engineering, supply, reticulation, quality control, placement, drainage, ground support, strength performance, safety, and planning and scheduling.

Although comprehensive, the following text is not considered exhaustive. The site specific nature and challenges of backfilling are such that that no one person can possibly understand every aspect and issue associated with the subject. Additional and different views to those given in the text are inevitable and the one hope is that this paper provokes thought and rigorous debate amongst the experts in the field. Without such debates, the science and engineering of backfill will not continue to prosper in the future.

\section{$2 \quad$ Systems engineering approach to mine backfill design and operation}

Where applied, mine backfilling is an integral process within the system which controls the flow of ore through a mining operation. This system includes ore processing due to several factors: the common use of mill tailings or other waste products as a component of the mine backfill, the impact of backfill dilution on mill ore grades and, in specific cases, the metallurgical performance associated with cement products in the ore stream. As such, the backfilling process needs to be designed and operated appropriately within the context of the global system design and operation. If managed in isolation, mine backfilling could lead to serious consequences in terms of human safety, environment and economics of the operation.

For most underground mining operations where backfilling is an option, the choice of whether or not to backfill, and if so, what backfilling method is most appropriate, ultimately needs to have a sound economic justification. Even decisions regarding health, safety and environmental issues have a fundamental economic basis. The choice should be which backfilling strategy is the best financially for a given safety or environmental outcome, rather than which backfilling strategy is safer or more environmentally sound. Licence-to-operate criteria are also ultimately economic decisions.

Every mining operation has unique issues to manage, so it is important to not select a backfilling method just because it is the 'flavour of the month', it has 'always been done that way', or it is 'what is comfortable' 
based on the personal experience of the decision makers. Choosing the wrong backfilling method can materially affect the economics of a mining operation.

Excellence in backfill research, technical design and operations do not necessarily produce the best outcome for a mining operation. Only when considered in the context of an economic outcome for the mining operation can the level of success be quantified.

Mine backfill primarily influences economics of the mining operations by affecting the total reserve of high value ore, and the rate at which this high value ore can be extracted at minimal dilution, within a given footprint of developed orebody. This can be a complex economic equation when factoring in the cost-benefit trade-offs between different backfilling strategies. In larger operations, the economics can also be influenced by the option to increase development costs and open up a greater mine footprint in order to access higher value ore early in the mine life that is less influenced by high cost backfill. In such cases, the additional cost of development (lower intensity mining option) can be traded off against the higher cost of backfilling (higher intensity mining option) for the same output of high value ore.

Care must be taken to ensure that the interdependency between these economic drivers is fully understood. For example, driving down backfilling cost by reducing cement content may inadvertently increase ore dilution from poorly performing backfill exposures. Alternatively, increasing cement content will raise costs, however, it could increase productivity (and hence value) through improved mining system cycle times.

It is also important to ensure that the total backfill system costs are included when deciding between different backfilling strategies. Examples of costs that need to be included (where appropriate) are differential capital and operating costs of mine development associated with backfill reticulation and disposal costs associated with tailings material that would be incurred if the tailings were not utilised as backfill (including tailings dam rehabilitation costs).

Economic measures will vary from operation to operation, and it is important to understand what these are, and how opportunities in the backfill operation can most influence these. For example, longer-term economic drivers favour backfilling strategies that increase mining reserve even if the costs of backfilling are significant, whereas shorter-term economic drivers discourage backfilling due to the high cost without immediate revenue benefit to quickly recoup the investment. Mining operations are typically managed differently through economic cycles and it is important that backfilling strategies do not fall victim to this cyclic nature of cost management without understanding the consequences of such actions.

Backfilling costs can be significant, typically up to $30 \%$ of total mining costs, therefore it is important that cost drivers are fully understood and backfill performance is not adversely compromised during any cost rationalisation project.

Backfilling signifies the end of one mining cycle and usually establishes the beginning of the next mining cycle within a given mining area. It is therefore the key part of the system that integrates one mining cycle to the next. If it is not managed properly then it can result in inefficiencies in the mining cycle, leading to longer mining cycle times (lower productivity), increased costs, ore loss and ore dilution.

Reliability and flexibility are key features of a backfill system that effectively supports a mining operation. Unpredictable performance can lead to unacceptable interruptions in the mining cycle. Variability in other parts of the mining system can lead to unplanned impacts on backfilling where there is a need to respond appropriately, e.g. backfilling quickly to support an unplanned, unstable mining void.

Because backfilling is at the extreme ends of the mining cycle that could range from weeks to years, the general impact on the day-to-day performance of the mine will not be as significant as other parts of the mining cycle. This is a double-edged sword. There is time to plan and respond to situations that could impact backfilling performance, but there also is time to create adverse situations due to poor backfilling practices, that do not affect short-term mine performance but are difficult to recover from in the longer term. 


\section{Backfill supply}

At some time after achieving a sustainable production rate, any mine that uses backfill will reach a stable volume of stoping void. At this time, the demand to fill stoping voids will essentially be volumetrically equivalent to that of ore production. Such high demand for backfill material supply encourages utilisation of the cheapest material available in order to keep mining costs under control. For this reason, waste rock from underground development, waste material from onsite processing facilities and locally quarried rock are the three most common forms of backfill material.

The above supply-demand balance is inevitable for a sustainable operation, therefore it is imperative that this backfill demand is well understood, sufficient capacity is built into the supply of backfill, and ongoing annual backfilling budgets are adequately costed. The latter requirement presents a particular challenge during low periods in the economic cycle, but insufficient funds to support sustainable backfilling could have legacy impacts during later high periods in the economic cycle if ore production rates cannot be achieved as a result of backfill constraints.

Additives to backfill to modify its properties (such as binding agents) can be very expensive, particularly if they are novel and not readily available or manufactured in large quantities. Even if such additives produce a quality backfill product, they can push up the cost of the backfill and render the overall mining cost unattractive.

Since backfill is an engineered material, quality control of supply must ensure that in situ specifications of the backfill material (e.g. strength, permeability, moisture content), are within their tolerance limits. Excursions can result in unacceptable safety and cost implications.

Because of the high cost of backfill, there should be in place an ongoing search for cheaper products. This must be balanced against the required specifications to ensure that backfill performance is not compromised in the quest for cost reductions.

Reliability of backfill supply is critical. Backfilling is a key component of the mining cycle and compliance to the underground mine schedule can be materially affected by poor backfill reliability. This could result in production targets not being met, or mining costs being elevated in order to access additional sources of ore that are not immediately dependent on backfill in the mining cycle.

Where backfill supply is based on waste material from a processing facility, an effective management structure and performance measures need to be set up to ensure a well-integrated system between mine and processing facilities that produces a reliable, quality backfill product. As part of the management structure, production of the backfill should be managed by people with appropriate minerals processing technical and operational experience to maximise the efficiency and reliability of production. This is particularly the case for the more complex backfill products such as paste fills.

For hydraulically-reticulated backfill, design of the backfill plant should consider both medium and long-term future reticulation strategies. In particular, the following issues need to be considered:

- The changing location of stopes relative to the fill plant, as the mine expands over time. This could require major additions to the fill plant to reticulate the fill to the new mine areas, and provision for such later expansions could influence the initial design of the fill plant.

- Replacement of existing boreholes. Where boreholes are used, if the life of the operation exceeds the life of these boreholes, then the fill plant design will need to accommodate replacement of these (and possibly future) boreholes.

- Inspection and service of boreholes. Where boreholes are used, the design of the fill plant will need to accommodate the ability to practically inspect and service these boreholes.

- Changes to material supply. Potential changes to feed material, e.g. from the processing plant, over time could result in changes to the backfill plant flowsheet to deliver the same backfill specification. 
All of these issues need to factor in the ability to continue filling in the active boreholes whilst work is simultaneously being carried out on other reticulation infrastructure in the same area. If not considered, significant downtime could result in the backfill system.

Where applicable, to accommodate growth of the horizontal footprint of the discharge from the backfill plant to the reticulation system over time, the backfill plant should be designed with the final product located at sufficient height above the ground to allow installation of adequate connections to the reticulation system. Without enough height, flow under gravity may not be adequate to cover the horizontal distance to the outlying reticulation infrastructure.

Where quarried materials are used for backfill, product specifications should be kept simple. An over-engineered product could be expensive and the incremental effort may be ineffective, particularly if the material naturally segregates when it is placed in the stope and results in a lower quality product than originally planned.

There is a need to be aware of the final product specification and to design the supplied backfill material accordingly, ensuring that changes to material properties during reticulation are taken into account.

\section{Reticulation of hydraulically-placed backfills - hydraulic fill, sand fill, paste fill}

The majority of wet fill systems utilise gravity as the cheapest and simplest way to reticulate backfill to the stopes. Driving head in vertical sections of the reticulation system is used to push the backfill along the horizontal sections. Depending on the rheological properties of the backfill, pipe characteristics (e.g. diameter) and ratio of vertical to horizontal distance travelled, there may not be sufficient driving head to achieve the required flow rate. In such situations, one or both of the reticulation system and flow properties of the backfill need redesigning. In paste fill systems where larger driving heads are necessary, this may require careful choice of backfill plant location and non-gravitation methods of transporting the backfill horizontally in some part of the reticulation system. Pumping is one option, however, this is usually expensive and difficult to manage reliably. Conveying of the paste is also an option that has been successfully implemented.

\subsection{Vertical or subvertical reticulation down shafts or boreholes}

Large vertical distances can create issues with managing very high pressures. The potential energy in the backfill needs to be controlled in a robust manner so as not to create unacceptable safety risk in the underground operation. One way to achieve this, where possible, is to divide the overall system into a series of vertical and horizontal sections to reduce the maximum pressure in the system. In cases where this is not possible, good engineering design of the pipework (including understanding of the flow behaviour within the pipe system) is essential.

Vertical or subvertical sections of the reticulation system that are contained within boreholes present particular operational challenges. These challenges are magnified by limited access to facilitate effective management.

Progressive deterioration of the borehole resulting from wear by the backfill is the most significant issue to manage. Depending on the characteristics of the country rock, a decision may or may not be made to case the borehole to minimise the rate of wear. Casing can also be problematic - in regions of wear the casing can create obstacles that can also lead to blockages. High wear-resistant casing can be used, but this can be expensive.

Wear in the vertical section does not only cause problems locally, but the material worn from this location, if it occurs as discretely separated pieces of rock or borehole casing, can cause blockages downstream. This situation tends to increase in frequency as the wear regions grow and can materially impact the reliability of the backfill system. 
The region of greatest wear, in both pipes and boreholes, is at the location where the free fall flow meets the phreatic surface of the fluid column, due to the high degree of turbulence created. It is important to understand where this location exists so that it can be effectively managed. Modelling of the fluid flow in the system will help predict behaviour. This critical location in the vertical column will vary depending on the resistance (due to pipe length and diameter) of the downstream horizontal section, and it is important to understand how often this length changes (due to changing distances to stopes being filled) and how each change affects the location of this wear point. In boreholes, it is critical to ensure that phreatic surface is not within the vicinity of the breakthrough into the horizontal drive at the bottom of the borehole, otherwise there could be significant management issues with the integrity of the backfill infrastructure at this location and failure of the rock and subsequent flow of backfill into the underground workings. To ensure that the phreatic surface is a sufficient distance above the breakthrough, a minimum pressure loss in the downstream horizontal section must be stipulated. This can be done by exceeding a minimum specified length of horizontal pipe (cascading the pipe back along the access drive more than once if necessary), using smaller diameter pipe, or incorporating an orifice plate within one of the pipe sections to increase pressure loss. With the latter, regular inspection and replacement of the orifice would be required to ensure its continual effectiveness.

Wear also occurs above the phreatic surface where the backfill flows in 'streams' down the pipe. This can cause high rates of localised wear which could also become problematic over time.

Managing wear in vertical sections requires constant monitoring and inspection. Various downhole surveillance devices are available to achieve this, although it can be problematic to get good information at the wear zone and beyond, particularly in boreholes where the damaged zone can physically limit the ability to collect good data.

At some stage when wear rates become excessive in a given vertical section, poor reliability could induce unacceptable risk to the productivity of the mining cycle. For pipes in a shaft, this could be resolved by periodic replacement in high wear regions. For boreholes, remedial plans could include relining the borehole, although this may be difficult or impossible to achieve, result in significant downtime of that borehole, and reduce its capacity. An expendable inner liner could be used, to be replaced frequently to protect a second, permanent outer liner. A low risk, although costly, option is to duplicate the borehole prior to the situation becoming critical. This would allow for the existing borehole to continue operating until it is considered inoperable.

\subsection{Horizontal reticulation in underground workings}

Underground development is expensive, therefore backfill pipes usually exist in major access drives. Exposure to underground operators is therefore a potentially significant risk that needs to be well managed. Backfill systems need to be reliable. Some key issues that need to be managed include: high pressures, pipe wear, line blockages, quality of installation and pipe damage.

- High pressures. The highest pressures during normal operation occur at the exits from the vertical sections of the reticulation system (either pipes or boreholes). These pressures need to be managed by appropriate engineering design. Where excessive pressures exist, these need to be reduced in a controlled manner, preferably in a location where exposure to general underground operators is restricted. This can be achieved, for example, by use of orifice plates, smaller diameter pipes, or cascade loops.

- Management of pipe wear. Progressive deterioration of pipes resulting from wear by the backfill will ultimately result in leakage and potentially pipe failure. Effective management strategies to minimise wear and prevent the consequences of wear include: engineering design, inner lining materials selection, regular inspection, pipe rotation and scheduled replacement. High wear areas should attract the most control. Sharp bends should be redesigned where possible with a high radius of curvature, or a large diameter wear box. Pipes can be installed under laser alignment to guarantee they are straight and thus minimise wear. Keeping the horizontal sections full of backfill 
will minimise wear (at the entrances to, and exits from, vertical sections). Pipe design should take into account dynamic loading effects, particularly in cases of progressive wearing at the pipe joint interface which could fail the pipe at the joint. Stiffening the pipe bracing and selecting appropriate joint design can minimise the effects of dynamic loading. Monitoring wear rates can be difficult in some areas and can be highly variable dependent on material properties of the fill and pipe. This should be considered in the design phase, for example, maintaining access to facilitate replacement of high wear components. Pipe weight is a function of wear resistance, therefore installation issues (cost, manual handling) need consideration.

- Line blockages. There needs to be a good management strategy around line blockages. Maximum pressures during blockages need to be understood and pipes designed to withstand failure under such pressure. Continuous monitoring of the reticulation system (complete with an effective early warning alarm), a good understanding of the behaviour of the system in the lead up to a blockage, and effective response procedures to reverse blockage conditions, can provide an effective process for minimising the potential for blockages. A blocked line can be very difficult to clean, particularly if the pipes are large diameter or the backfill contains cement that has cured. In the latter case, it is important to have a fast response procedure to clean out the pipes as soon as possible. Backfills containing coarser particles, e.g. sand, can demonstrate significant flow variability and have more chance of settlement and line blockage. Such dynamics can be dampened by deliberately increasing the driving head to minimise slack (less than full) pipe flow, for example, with the use of orifice plates. Procedures for effective flushing at the completion of each backfill pour must be developed to ensure that residual material is not retained in the pipes, thus avoiding a situation that could cause a blockage at the start of the next pour.

- Quality of installation. Quality installations and regular inspections are the key to predictable performance, therefore it is important to use high performing, experienced pipefitters.

- Pipe damage. Pipes in main accesses are subject to damage from vehicles. This could lead to pipe failure, which can be either immediate or delayed. To complicate this situation, there may be no awareness of the incident, for a number of reasons, and therefore remedial action may not be forthcoming. To avoid such situations it is important to ensure that pipes are isolated, e.g. separated by height or restricted access, or protected from vehicles by use of an effective physical barrier.

In all of the above cases, effective on-stream monitoring can provide early warning of deviations from standard operating conditions that could assist with rapid remedial action.

\subsection{General operational comments}

Understanding of the fluid flow behaviour in the reticulation system, in particular the dynamics in vertical sections is critical to effective operations. Flow behaviour is site specific, therefore there is a need to develop good data initially through monitoring and modelling, and to develop operational procedures that best manage the flow behaviour. These procedures need to reflect the short-term impact on flow behaviour as a result of the changing geometry of the system due to backfilling of stopes in different locations, and the longer term impact on flow behaviour due to extension of the system into new mine areas (where applicable). For these reasons, it is important that backfill reticulation is managed by personnel with appropriate technical knowledge and operational experience with flow behaviour of slurry and paste materials in pipes.

In some situations, the rate of backfill being placed in one stope may be limited by factors such as drainage and curing times. Rather than reducing the backfilling rate, or continually stopping and starting the backfill system to spread the flow over more than one stope, it may be preferable to split the flow and run to more than one stope simultaneously. This can be done a number of ways and will depend on whether the flow from the backfill plant is continuous, e.g. for hydraulic fills, or batched, e.g. for paste fills. 
Paste fills have a number of advantages over conventional hydraulic fills when being reticulated. Generally a pour can be stopped and re-started successfully without blocking the pipe because the paste does not settle in the pipe, however since paste contains cement, this benefit is limited in duration. Because of the stable flow properties, paste fills can be successfully reticulated vertically upwards as long as there is sufficient driving head. This can be an advantage if a stope needs to be filled above the mine access level in which the reticulation system is located, or the mine extends over time vertically upwards, relative to the existing backfilling system horizon. In the latter case, an extension of the backfilling horizon can be located higher in the mine and the paste fill can be reticulated upwards to this new horizon. In these situations, robust procedures must be in place to ensure that the pipe is adequately flushed at the conclusion of each pour.

\section{$5 \quad$ Reticulation of dry backfills}

Dry fill is commonly tipped directly into a stope via a truck or a loader. In this situation, the primary issue is to ensure that the activity is made safe because operators are working close to an open void. Layers of control should be put in place to minimise the consequences of operator error, equipment failure or ground failure. As examples, a chute could be installed to keep the equipment away from potentially unstable stope walls, or a winze could be excavated from the loader/truck access into the stope and rock tipped down the winze.

Where the dry fill is being tipped into a stope and the backfill itself forms the working floor as the stope is progressively filled, appropriate procedures need to be in place to ensure that ground support above the tipping areas is adequate, stability of the working floor is managed, and exposure to the backfill rill is well controlled.

More complex dry fill systems can exist, especially where combinations of hydraulically-reticulated (including cement slurry) and dry fills are mixed together. Such mixing can occur on the surface, underground prior to being transported to the stope, or at the discharge location into the stope. Methods of transport can be directly from the surface via borehole into the stope, in pipes (hydraulically), via rock passes, along conveyor belts, in trucks, or in loader buckets.

Where material is being transported down rock passes, these passes need to be well managed to ensure that backfill supply is reliable. This includes management of hang-ups, and condition monitoring and control of the rock pass and associated discharge infrastructure at the base of the pass.

It is also important to understand the degree of attrition (particle degradation) that occurs in the rock pass, in cases where particle size distribution is critical to performance characteristics of the backfill.

Effective management of the aforementioned issues is likely to be influenced by the choice of whether or not to choke feed the fill material down the rock pass.

The choice of the materials handling system to transport dry fill in the underground workings depends on a number of factors, namely the scale of operations, source of dry fill (centralised versus decentralised), required flexibility, capital versus operating costs (including mine development requirements), preference between batched and continuous discharge into the stope, relationship with wet fill supply (where applicable), and relative safety aspects.

\section{Quality control}

Backfill is an engineered product that is designed to achieve specific physical characteristics at a given point in time during the stoping cycle. Failure to achieve these specifications will result in a failure of the backfill to provide its designed function. The consequence of such failure will vary depending on the circumstances in which this event has occurred.

The failure to provide adequate function can be mainly attributed to two main causes:

1. Failure to adequately design the backfill (covered in other sections). 
2. Failure to adequately supply the components of the backfill to the stope, such that the final placed backfill does not represent the product that the design was based on.

The successful supply of the backfill components to the stope can be measured as a function of quality control.

Poor quality control can manifest itself in a number of different ways. Some key examples are:

- Poor quality of cement supply (or other binder). As a general rule, quality of cement supply is governed by sourcing of cement that is guaranteed to meet recognised industry-wide quality standards. Provision of regular reports of test work to support the quality clause should be included as a standard part of the supply contract, to ensure that the quality is maintained on an ongoing basis. Where quality of binder supply is not guaranteed according to such standards, an ongoing, rigorous quality control process should be carried out in-house within the mine operation in order to maintain adequate quality of the backfill. This may involve, for example, regular testing of laboratory scale backfill samples.

- Poor control of cement (binder) dosage rates. If the cement is not dosed into the backfill at the correct rate then it will either cost more than planned if overdosed, or fail to perform its engineering function if under-dosed. Effective monitoring systems should be installed and adequately maintained within the backfill supply plant. Such monitoring needs to be undertaken with both the cement and backfill supply to ensure that the correct percentage of cement is achieved in the backfill. As a backup, regular (daily, weekly) cement stock reconciliations should be made to confirm that the dosage rate is according to plan.

- Change in backfill particle size distribution. Over time, the size distribution of the backfill may change. This could be due to changes in specification of the material supplied for use as backfill (e.g. tailings from concentrator, crushed rock from quarry) or changes in the backfill production process over time (e.g. wear in cyclones, crusher jaws). Changes in particle size may also change the amount of water retained in backfills that have a slurry component. Both changes could adversely affect backfill performance. To manage this issue, it is important to undertake regular tests to ensure that the particle size distribution of the backfill is maintained according to its engineering specification.

- Excessive water dosage. In piped backfill reticulation systems, large doses of water are used from time to time as part of standard operating practices. Such situations include cleaning of pipes at the end of a backfill pour to prevent build-up of material (leading to poor flow rates including total blockages), and corrective action when a pipe starts to block during normal operation. In such situations, this excessive water may compromise the performance of the backfill in the stope and should be managed accordingly. Tolerance limits should be placed on the quantity and frequency of such water addition events, and if these limits are exceeded, then the situation is escalated and necessary actions are taken to ensure that the quality of the backfill in the stope is not compromised. It is also important to inspect for ingress of water into any stope being filled, e.g. through rock structures and drillholes, that could significantly influence performance of the backfill. Where possible, these conduits for water should be sealed. Where it is not possible to prevent water ingress into a stope, appropriate action needs to be taken to prevent this water from adversely affecting backfill performance, e.g. slowing rate of filling to allow for more drainage time, increasing cement content to offset impact of additional water.

- Unplanned segregation of constituent materials upon placement in the stope. This is covered in the following section.

- Changes in operating practices. Over time, and in particular with turnover of people with technical experience in the backfill system, intentional or non-intentional changes in operating practices may result in deviation of backfill characteristics from original specifications. It is important to have in place a procedure for regularly checking that backfill produced meets original 
specifications, e.g. annually. Contained within this procedure should be a description of the reason for each specification, to ensure that such knowledge and understanding is preserved. Where changes in engineering specifications of the backfill are deliberate, effective change management procedures need to be followed and changes in both specifications and operating procedures documented.

Where cemented backfill is used, regular laboratory scale tests are recommended as part of a general quality control program. It needs to be recognised, however, that a successful test program does not necessarily guarantee planned backfill performance. If the supply, reticulation or placement of backfill has an impact on the final in situ characteristics of the backfill and these are not adequately represented during sample preparation of the laboratory specimens, then in situ performance of the backfill could be overstated relative to laboratory specimen performance.

\section{$7 \quad$ Placement of backfill in a stope}

Segregation of constituent materials, based on particle size and phase (solid versus liquid), can occur whilst the fill is airborne within the stope, when the fill impacts against stope walls or the surface of the fill mass, and when the fill flows down the fill surface as it cyclically builds up and fails once its shear strength is exceeded.

This segregation can result in layering containing differential strength and/or permeability characteristics within the fill mass. Where this potentially has a material impact on strength or drainage performance, segregation needs to be understood and procedures put in place to minimise its occurrence.

Segregation is a complex process that is difficult to predict and the impacts are not well recognised or understood. Poor strength of segregated backfill containing lower than planned cement content have been attributed to failure on fill exposures, and drainage performance is influenced by layers of differential permeability within the fill mass.

The following generalised practices are recommended, where segregation is an issue:

- Maintain a maximum particle size of less than $75 \mathrm{~mm}$. Particles greater than $75 \mathrm{~mm}$ have a greater chance of segregating.

- Introduce wet and dry fills into the stope from the same location. The easiest way to cause segregation is to place constituent materials into the stope at different locations. Make sure that the trajectories of the wet and dry fill components on entry to the stope are aligned. Vertical trajectories are easiest to manage and guarantee the best probability of good mixing in the stope.

- Ensure that the fill is going into the stope where expected, through regular monitoring. Changes during stope filling, e.g. pass wear, can change the trajectory and cause unplanned segregation.

- Determine the maximum ratio of dry to wet fill that can be tolerated before segregation critically impacts performance of the backfill. This ratio may be different depending on whether the wet and dry fill components are pre-mixed, or whether the dry fill component is delivered in batches or continuously tipped into the stope.

- Where stopes are filled with hydraulic fill, minimise the quantity of free water at the surface of the backfill, as this tends to create layers of differential permeability (as ultrafine particles are filtered out of the surface water as it drains through the fill surface).

Segregation potential is very site specific and it is important that operations recognise and understand their own individual situation and develop appropriate management plans. Within an operation, segregation effects can be stope specific, therefore operational management should be conducted on a stope-by-stope basis. 


\section{Drainage of water}

In backfills that contain a slurry component, water may freely drain from the fill after it has been placed in the stope. The rate of water discharged will depend on the rate of backfill placement, placed water content, retained water content and permeability of the backfill.

In these situations, the backfill needs to be allowed to drain freely in order to prevent progressive build-up of pore pressure in the backfill. Excessive pore pressure can lead to failure of barricades that have been constructed to prevent the backfill entering access drives surrounding the stope during filling operations. Failure of these barricades could lead to uncontrolled flow of backfill into these access drives.

To prevent build-up of pore pressure, these barricades need to be appropriately designed to allow for adequate drainage of free water. This could include construction using permeable materials, and installation of effective drainage pipes. There are numerous examples worldwide of how this has been achieved, however it is critical that barricades are designed for each specific backfilling situation. What is appropriate for one mining operation is not necessarily appropriate for another operation.

The barricade installation, including associated drainage equipment, needs to be designed such that water is allowed to drain freely without permitting solid fill particles to discharge. When fill particles are allowed to leak through the barricade structure, the process of 'piping' can initiate, where stable, high permeability channels can form in the backfill resulting from erosion of fill particles in the channel. These erosion channels, or pipes, can propagate through the backfill in a direction against the pressure gradient and therefore generate increasing pressure against the barricade. If this pressure exceeds the strength of the barricade then it can fail.

Piping is a complex fluid flow process that has a number of potential scenarios. For example, if the backfill does not tightly fill the access drive behind the barricade, then it is possible for piping to occur in the fill mass without discharging fill through the barricade. It is therefore important that there is good, site specific understanding of the drainage behaviour of backfill in order to successfully manage the associated risks during stope filling.

Similar pipe structures can form where backfill discharges through open drillholes, rock fractures, joints or faults that intersect both the stope and surrounding access drives. Apart from the issues associated with uncontrolled discharge of backfill into these access drives, there is potential to impact performance of adjacent barricades if there are adverse pressure conditions formed in the backfill as a result of such events.

To minimise the potential for issues associated with drainage of water, the highest slurry density should be targeted that allows the backfill to be reticulated safely and reliably at the required flow rates. This will minimise the amount of water that will drain from the backfill. Opportunities should be considered to change the specification to reduce water drainage without compromising other performance metrics.

Operational procedures can also be employed to reduce the risk of adverse conditions during drainage events. For example, periodic rest events can be employed where backfilling is stopped to allow the backfill to continue draining without further inflow of water. This reduces the height of the water column in the stope and hence reduces pore pressures. Also, changes in stope design (including number and location of barricades) can be considered to reduce pore pressures. Effective backfill drainage modelling can greatly assist in this process.

Consequences of barricade failure are very situation dependent and can be difficult to predict. Key influences include: the amount of backfill mobilised by the failure, saturation level in the backfill, strength attained in the backfill at the time of failure (both cohesive and frictional), flow characteristics of the backfill (Newtonian versus non-Newtonian behaviour), quantity of surface (ponding) water present, and geometry of the access drives affected. Outcomes can vary, and include from least to greatest impact: cracking in the barricade structure, failure of the barricade only (local impact), failure of the barricade and minor discharge of backfill (plus water) into the local access drive, and failure of the barricade and major 
flow of backfill extending a significant distance along access drive(s). Safety of personnel within the surrounding area is correspondingly impacted by the severity of the outcome of the barricade failure.

It is important to ensure that barricades are designed as fit-for-purpose, based on sound engineering principals. Good quality control and assurance practices should be employed during construction, to ensure that barricade performance meets the design criteria. Since barricade construction often occurs in dynamic work environments where access is difficult and ground conditions are challenging, the quality of barricade construction can be compromised if not managed well.

\section{$9 \quad$ Regional ground stability}

Backfilling has the primary function to maintain local and regional ground stability around stoping areas in which rock stability is usually structurally controlled. Failure in this rock can be time dependent which adds a degree of complexity to operational management of ground stability. There is always a temptation to delay backfilling, particularly if backfill supply is not meeting demand or cost pressures are present. Leaving a stoping void open that is not linked to future production in the near-term, or extending the bench stope a few more rings to meet a production target, are examples of such decisions that can be made. The consequences of these actions on ground stability, both locally and regionally, could be very costly to the mining operation. In such situations, early stability of the rock could result in apparent justification for the decision to delay backfilling (and potentially fostering repeated similar decisions), only to find that failure over time results in consequences ranging from sterilisation of surrounding ore to large scale destabilisation of the regional mining area.

With sound geotechnical design, backfilling strategies should be adhered to, in order to maintain the integrity of the regional rock mass. Changes to backfill practices should be carefully considered and implemented, with full understanding and management of the potential risks.

Tight filling of a stope void, where this is required, should have a sound backfilling operating practice to achieve this outcome. Failure to tight fill could have consequences in terms of regional ground stability, and can also adversely affect the ability to successfully extract adjacent stopes. Tight filling can be challenging because stope crowns may not be geometrically favourable to achieve a successful outcome, especially in situations where these crowns are flat or shallow dipping. The most successful tight filling occurs when the backfill enters the stope at the apex of the stope crown and the dip of the crown is steeper than the angle of the backfill surface. This is not always possible to achieve easily, although practices can be employed to improve tight filling potential, including reducing slurry density of the backfill when tight filling, and changing the discharge location to the apex of the crown during tight filling if the discharge location was elsewhere, e.g. in the centre of the crown, during the normal filling operation. In situations where tight filling is difficult, but critical to regional stability, then every effort should be made to complete the tight filling process. As an example, overbreak that has resulted in a stope crown being above the fill reticulation horizon could potentially be filled by drilling an inclined borehole into the stope crown and reticulating the backfill up the borehole. This would require understanding of the flow behaviour of the backfill to ensure that it could successfully be reticulated up an inclined borehole. As another example, the crown of a stope could be redesigned specifically to facilitate tight filling, where this is critical to maintaining regional ground stability.

\section{Backfill strength performance}

Strength performance of backfill can be categorised into performance during and after placement. During placement, the backfill needs to attain sufficient strength over time to prevent barricade failure due to excessive static (earth pressure) loading. This is a separate issue to hydrostatic loading of the barricade from water draining through the fill, although the two processes may act in conjunction to contribute to overall pressure applied to the barricade. Barricades need to be designed to withstand static pressures applied by the backfill, and this should be based on static models that predict such pressures based on the rate of loading in the fill column and resistive forces due to frictional and cohesive properties of the backfill 
as they change over time. For paste fills, reliance on cohesive strength gain over time as the fill cures is much greater compared with conventional hydraulic fills where inherent frictional properties limit the amount of static pressure imposed on the barricade. For these paste fills, operational procedures such as periodic rest times during the pour (particularly once the fill level has gone through the top of the barricade) can assist by providing more time for the backfill to gain strength, for a given height of fill column achieved in the stope. Also, cement content can be increased to raise the rate of strength gain. Good quality control of the filling process is required to ensure correct cement dosage and rest periods are employed, particularly with small plan area stopes where there is a significant rate of height gain over time in the fill column. Lack of good operational control of these processes heightens the risk of barricade failure, the consequences of which could be similar to those experienced when barricades fail under hydrostatic loading. To offset potentially high labour costs associated with manual control, consideration should be given to automated controls, such as pressure and flow rate monitoring, alarms and automatic shut off controls.

As mentioned previously, it is important to ensure that barricades are designed as fit-for-purpose, based on sound engineering principals, and are well managed during construction.

Strength performance in the backfill after placement is largely related to its stability over an exposed surface resulting from adjacent stoping. Performance specifications, and backfill specifications to achieve such performance, can be quite varied, depending on stoping method, and exposure method, sequence and geometry.

Strength performance on backfill exposures can be divided into two categories, namely dynamic (due to blasting) and static (due to self-weight loading within the backfill). The impact of dynamic loading is not well understood, however in situ observations suggest that the depth of failure due to dynamic loading is a function of cement content, curing time, width and height of exposure, and blasting geometry relative to the backfill. The author's experience indicates that failure due to dynamic loading for exposures up to $30 \mathrm{~m}$ wide are of the order up to $5 \mathrm{~m}$ in depth, although there could be some static-related failure contributing to such outcomes. Typical failure shapes are arched across the width of the exposure, with the maximum failure depth towards the centre of the exposure. There are a number of operating practices that can be employed to manage the impact of dynamic loading, including providing a standoff distance between blast holes and the backfill mass, blasting in a low confinement environment, using lower powder factors adjacent to the backfill, and specifying a lower limit on curing times prior to blasting.

Static performance of backfill in open stoping has been extensively researched in the past and has demonstrated that the mechanism of arching dominates loading conditions in the fill and hence controls the potential for failure. Arching is the mechanism where some part of the self-weight loading within the fill is transferred to adjacent material and therefore stresses within the fill do not increase with depth to the degree that would occur in a free standing column of fill. Therefore the potential for static failure within the fill is reduced. Arching is greatest when the adjacent material is rock (due to the difference in stiffness, more load from the backfill is transferred to the rock), less when the adjacent material is fill, and zero when there is an adjacent void. Since the loading environment is three-dimensional, then, typically with four sides to a backfill mass, one is adjacent to a void (the stope being mined) and the other three are a combination of rock and backfill, which control the arching process. The arching mechanism is better understood against rock support and least understood against backfill support, although modelling work carried out by the author suggests that backfill support has approximately half the impact (in terms of arching) relative to rock support. It is recommended that static loading within the backfill is estimated using modelling techniques in order to determine strengths (and therefore binder addition rates) that are required to manage backfill dilution.

Static performance is a function of backfill strength which in typical applications is a function of particle size distribution, density, cement content, retained moisture and curing time. Where possible, laboratory strength testing should be based on samples cured in an environment (temperature, humidity and curing time) that reflects in situ curing conditions prior to exposure of the backfill into an adjacent stoping void. 
Triaxial strength testing is recommended to provide strength performance over a wide range of confining pressures which are representative of the in situ loading environment, with sample dimensions large enough to ensure that the largest backfill particles within each sample do not adversely bias the strength measurements. Care must also be taken to correlate laboratory strengths with equivalent in situ strengths, where there is a differential degree of segregation of constituent materials within the backfill, or a differential degree of packing (either more or less in the laboratory sample relative to the in situ sample that it is attempting to represent). Both effects can be quantified by comparing the densities of the laboratory and in situ samples.

The influence of retained moisture on in situ strength is not well understood, however there is a strong correlation between strength and retained moisture in laboratory samples. Anecdotal evidence suggests that backfill continues to drain long after placement (including paste, albeit at a very slow and undetectable rate), with a corresponding increase in strength over time.

Backfill stability can be influenced by a range of unplanned and unpredictable events. These include: operational indiscretions such as tipping waste material into the stope and not accounting for the effect on stability, poor measurement of stope geometry prior to backfilling which influences design of the backfill and subsequent extraction of adjacent stopes, and unplanned failure of stope walls during stope filling which could result in pockets of low strength material in the backfill. Through good backfill management practices, such events need to be either minimised in frequency, or responded to with effective corrective actions once they occur.

In applications where the fill is placed and later exposed by mining from below, then the backfill needs to be stable in the undercut. Once again, arching dominates the loading in the fill, however this time all the weight of the fill needs to be transferred to the adjacent material in the abutments. The backfill therefore needs to be strong enough to withstand the significant shear stresses that will be present to allow the transfer of all load to the abutments. If it is not, then the fill will fail until the shear stresses are reduced to match the shear strength of the fill. This will create an arched profile in the fill, with the apex of the arch towards the centre of the fill exposure. The amount of fill failure that occurs will be a function of the fill strength, fill density and width of exposure. Operational practices to manage this process include increasing the cement content in the fill to a defined thickness directly above the exposure, and strengthening the fill with surface and bulk reinforcement, e.g. mesh and bolts, during placement of the backfill.

In specific narrow bench stoping applications, static performance of uncemented rock has been applied to minimise dilution of the rockfill into the ore. This application is typically focused on low grade tabular orebodies that are surrounded by poor quality rock that cannot support itself over large open spans within the stope. In these cases, low value backfill needs to be placed as close as possible to the mining front in the stope to minimise wall exposure. Experience has shown that in some cases, blasting directly against the backfill can compress it to a degree that it gains sufficient strength to support itself. This allows for shorter open spans and reduced backfill dilution in the ore during stope firings. To a large degree, success of this practice is largely experience-based and site specific. Because it is not engineered, quality control of the backfill performance could be somewhat problematic.

During the mine design process, there should be a trade-off between the impact of backfill dilution and the impact of practices that reduce backfill dilution. This trade off needs to consider the full value proposition for the mining operation, not just costs. For example, reducing stope cycle time by shortening backfill curing times could have a more positive impact on value (increasing mine throughput) than the associated cost of additional dilution in the ore. Ultimately there will be a balance that is site specific. What is appropriate in value terms for one operation probably won't be appropriate for another operation, even if the cost impact is similar.

Backfill strength is also a key factor in the engineering design of excavations through backfill, in operations where mining through backfill is required to gain or maintain access to sections of the underground in order to sustain production. Consideration should be given to adjusting the strength requirement in backfill where future excavation through this backfill is required. This will need to be planned for during stope 
design to ensure that cement contents are adjusted at appropriate times during stope filling to factor in these strength requirements in the backfill. Once filled and cured, the backfill can then be driven through using appropriate excavation and surface support techniques, for example, low energy drill and blast followed by a fibrecrete/mesh/fibrecrete support application.

\section{Safety}

Safety management of backfill systems in an underground operation needs to be focused on the provision of a safe working environment for personnel who are directly involved in the backfill operations, as well as general mine personnel who are working within areas that are exposed to potential safety issues associated with the mine backfill.

Safety leaders at the mining operation need to recognise that backfill systems are continuously changing over a range of time scales, and that operational practices and procedures need to be responsive to such a dynamic operating environment. Such time scales include:

- Within a given backfill pour, due to flow dynamics.

- From one backfill pour to the next, due to changing height (and hence location) of backfill in stopes being filled.

- From one stope being filled to the next, where major components of the reticulation system are modified (moved, extended, retracted), and a different area of the mine, adjacent to the new stope being filled, is directly impacted.

- As the mine grows, where the reticulation system undergoes major extension.

- As potential changes occur to backfill supply characteristics over time, e.g. particle size, water content.

From a safety perspective, a well-managed backfill system should include the following key characteristics:

- Management of backfill operations by people with appropriate technical and operational experience.

- Quality control of material supply.

- Sound engineering design of the backfill system, including backfill performance specifications, and design of component infrastructure and equipment.

- Online monitoring and control of backfill production, reticulation and placement.

- Regular inspection and maintenance procedures.

- Risk management through the hierarchy of controls.

- General underground operator awareness of backfill practices through underground mine inductions.

- Specific inductions and competence training for personnel directly involved in backfill operations.

- Integration of backfill safety into general underground safety management practices.

- Appropriate change management practices for modifications to the backfill system that have a material impact on operator safety.

- Continuous benchmarking against best practice in backfill safety management.

- Rigorous investigation of significant incidents that involve the backfill system, whether or not they cause injury, with a view to implementing corrective actions to prevent repeat occurrences. 


\section{$12 \quad$ Planning and scheduling}

Effective planning and scheduling of a backfill system can be a complex exercise that incorporates a number of major production areas on the mine site. Typically, processing waste streams that are used as backfill have minimal storage capacity and this parasitic nature of supply requires well integrated planning and scheduling functions between the mine and processing plant.

An integrated mine schedule that includes stoping and backfilling activities is recommended to ensure that backfill supply and demand are constantly updated and balanced. The mining schedule tends to constantly change in response to factors such as unplanned stope and equipment downtime, and stope overbreak and/or underbreak events, and the backfill schedule needs to be regularly updated to effectively respond to such changes, so as not to materially impact the overall mine plan. Production schedules that contain contingency may not be effective if they are not integrated with the backfill schedule, as the consequence could be greater demand or variation on the backfill system than planned.

The backfill system needs to be sufficiently flexible to quickly respond to changing demand, for example, if a stope needs to be filled quickly to either prevent stope wall failure or arrest an existing stope wall failure event. This is particularly the case in variable or deteriorating ground conditions. In stopes where there is a reasonable chance of failure events that need controlling, it may be critical to set up the backfill reticulation system prior to stope production occurring and have procedures in place that can allow a rapid response if failure initiates. As a minimum, the backfill system should be put in place towards the end of stope production as this is when the stope void is at its largest and most prone to unplanned failure that may need controlling.

In general, more stopes are mined at any given time than are filled, therefore the backfill system needs to be reliable. Failure of a reticulation system feeding a single stope that is the only one or maybe one of two stopes being filled at a given time will have much more impact on the mine schedule than the loss of production in one of many stopes online.

The focus on meeting ore production targets tends to keep the creation of stope void on schedule, however the same focus is not always applied to reducing stope void through backfilling. Ultimately poor utilisation of the backfill system will negatively impact production rates, therefore the focus on backfilling should be as strong as the focus on meeting the ore production schedule.

One of the biggest impacts on meeting a backfilling schedule is the delay in commencing filling of a stope due to poor stope closure. Removing the last $5-20 \%$ of stope tonnes can be slow progress due to the significant requirement for remote loading, and the constant potential for falloff from sidewalls and crowns (when the stope is at its largest and least stable state), which not only add to the tonnes that need removing, but generally add difficult tonnes due to poor fragmentation. Also, generally there are fewer loaders with remote capability and the availability of these loaders can be less than average due to the unfavourable conditions within which they operate. It is therefore appropriate to realistically schedule for additional time to close out stopes and ensure that there are an adequate number of available remote loaders that are given the appropriate priority to clean out the stope according to the schedule.

Measurement of stope voids using cavity measuring devices prior to and, if possible, during filling will assist with accurate backfill scheduling. Stope wall failures during filling could impact the volume of void to be filled, depending on how effective the backfill penetrates into the associated broken rock in the stope, and this should be monitored. This could also affect the stability of the backfill when exposed into an adjacent stope and should therefore be recorded and the information used to assist with design of this stope.

Stopes may vary considerably in size, therefore average backfill demand may vary significantly from instantaneous demand. For example a relatively large stope will not require backfilling for some time, which could result in reduced backfill demand during its production life. However when production has finished, backfill demand could rise sharply as this large stope will need to be filled in conjunction with other smaller stopes that also need filling. In such cases, peak backfill supply will need to be higher than average supply, the difference being related to the varied stope sizes in the production schedule. 
A common issue with backfill operations is that resourcing and scheduling occurs according to average demand. In such situations, peaks in demand cannot be met and supply cannot be fully utilised during periods of low demand, therefore the average performance ends up falling below average demand. This tends to delay backfilling, which can ultimately impact the ore production schedule.

Planning for sprint capacity in a backfill system is also recommended. Although this will add cost to the backfill system, the ability to manage unplanned events with opportunity to catch up to achieve scheduled void filling provides robustness to the high value stope ore production schedule. A trade-off study is recommended to confirm the overall value proposition of this strategy, incorporating realistic expectations on the impact of unplanned events.

\section{Summary}

Backfilling of stoping voids will continue to play a major role in a significant proportion of current and future underground operations, particularly where high grade zones in the mineral resource attract open stoping methods in order to extract the higher grade and leave in place the lower grade material.

The notional volumetric equivalence between ore mined and backfill placed, and the impact of mine backfill on ore recovery and dilution, will guarantee that backfill, where utilised, continues to have a material impact on the safety and economics of mining operations.

Successful mine backfilling operations are characterised by the following:

- Backfill systems need to be fit for purpose. Site specific issues need to be well understood and factored into the backfill system design.

- A high degree of technical competency is required in a range of engineering disciplines to successfully manage backfill operations.

- Safety management in backfill operations needs to be integrated into general underground safety management practices.

- Backfill systems are constantly changing and management practices need to account for such dynamics.

- Backfill planning and scheduling need to be integrated processes that incorporate both mining and processing operations. Backfill systems need to be sufficiently flexible and robust to adequately support the mine ore production schedule.

Successful management of mine backfill operations requires continual vigilance to maximise the value of backfilling, in the face of ongoing variations in short and long-term economic drivers and constantly evolving underground operational environments. The challenges that are presented within these operations provide a strong incentive for ongoing technical and operational development of mine backfill systems. 